Supporting Information

\title{
A Novel Antifungal Plasma-Activated Hydrogel
}

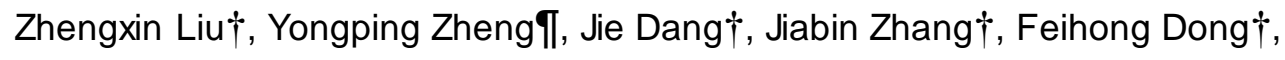 \\ Kaile Wang†, Jue Zhang† $\|^{*}$ and Jing Fang†ा \\ $\uparrow$ Academy for Advanced Interdis ciplinary Studies, Peking University, Beijing 100871, People's Republic \\ of China \\ II College of Engineering, Peking University, Beijing 100871, People's Republic of China
}

* Corresponding authors: Jue Zhang, Email:zhangjue@pku.edu.cn 
Table S1 Mechanical properties of different hydrogels

\begin{tabular}{ccc}
\hline Hydrogels & $\begin{array}{c}\text { Young's modulus } \\
(\mathbf{G P a})\end{array}$ & $\begin{array}{c}\text { Tensile break strength } \\
\mathbf{( M P a})\end{array}$ \\
\hline Control & 0.00278 & 0.03336 \\
PAH-2 $\min$ & 0.0026 & 0.02761 \\
PAH-5 $\min$ & 0.00226 & 0.03126 \\
PAH-15 $\min$ & 0.00114 & 0.02739 \\
PAH-30 $\min$ & 0.00075 & 0.03267 \\
\hline
\end{tabular}




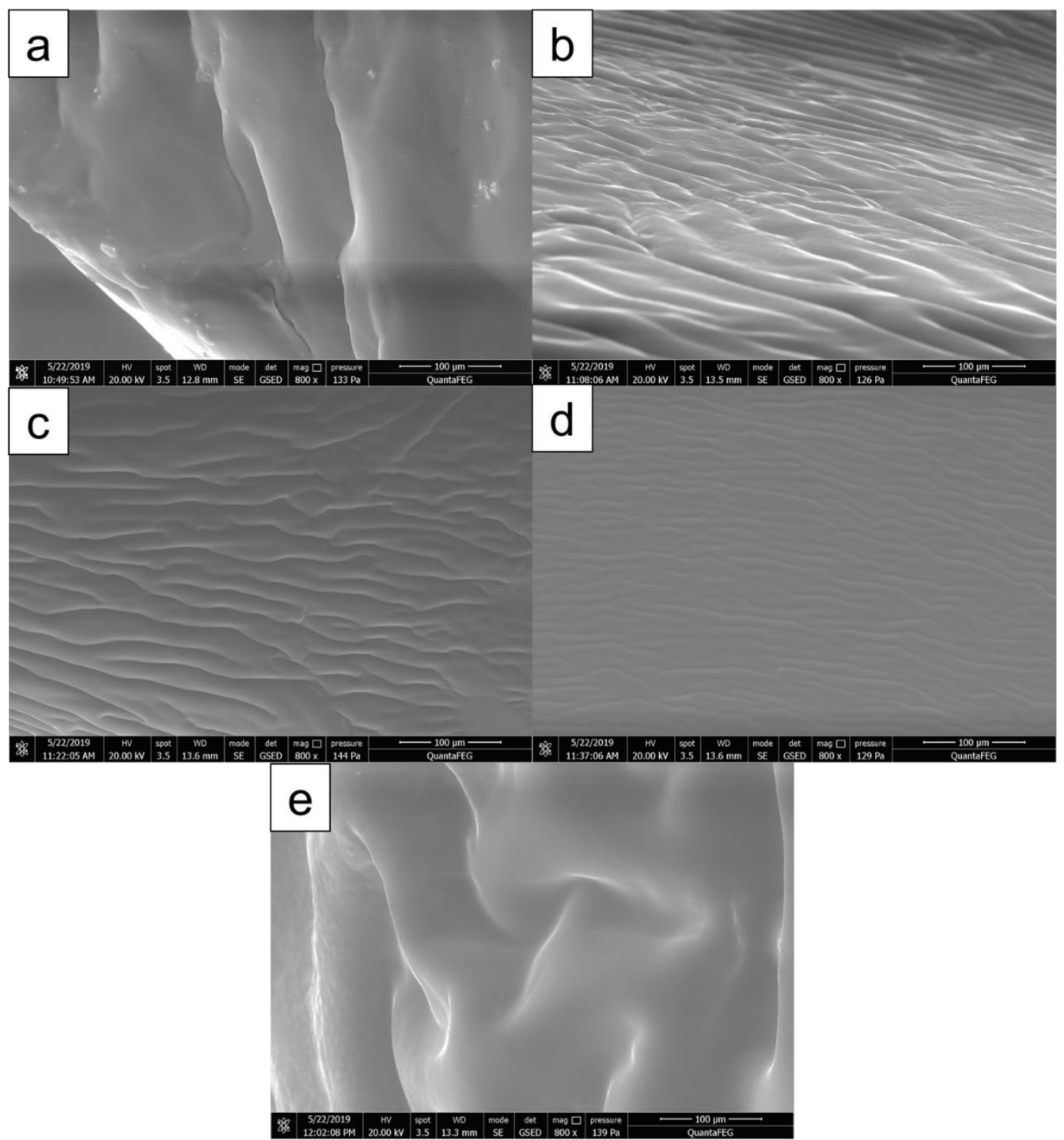

Figure S1. ESEM micrographs of different hydrogels: (a) conventional PAAm hydrogel; (b) PAH-2 min; (c) PAH-5 min; (d) PAH-15 min; (e) PAH-30 min 


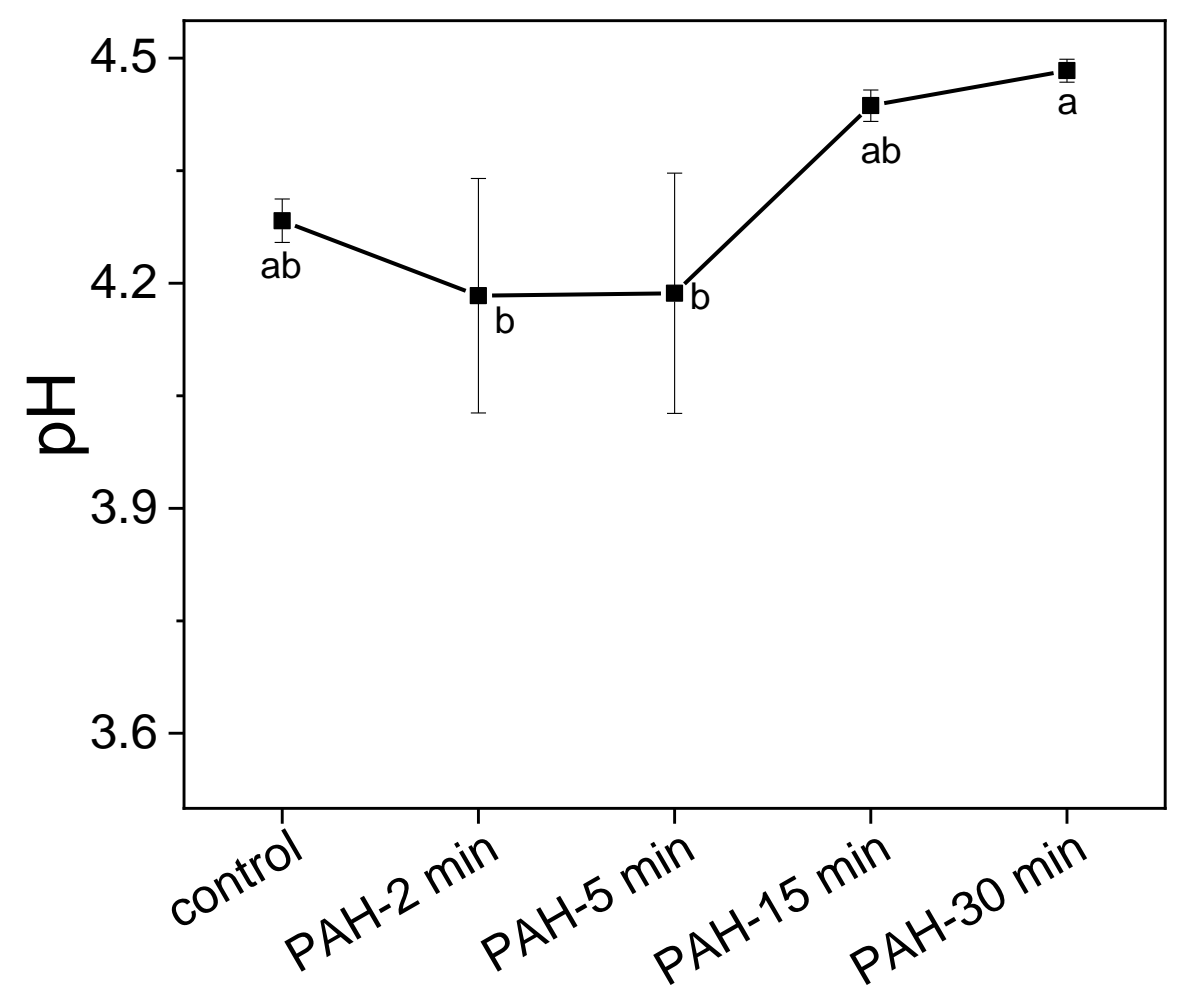

Figure S2. pH value of PAH and conventional PAAm hydrogels. Bars labeled with different lowercase letters indicate a significant difference according to the Student-NewmanKeul's multiple range test $(p \leq 0.05)$. Bars indicate average expression $( \pm S D)$ of three replicates. 

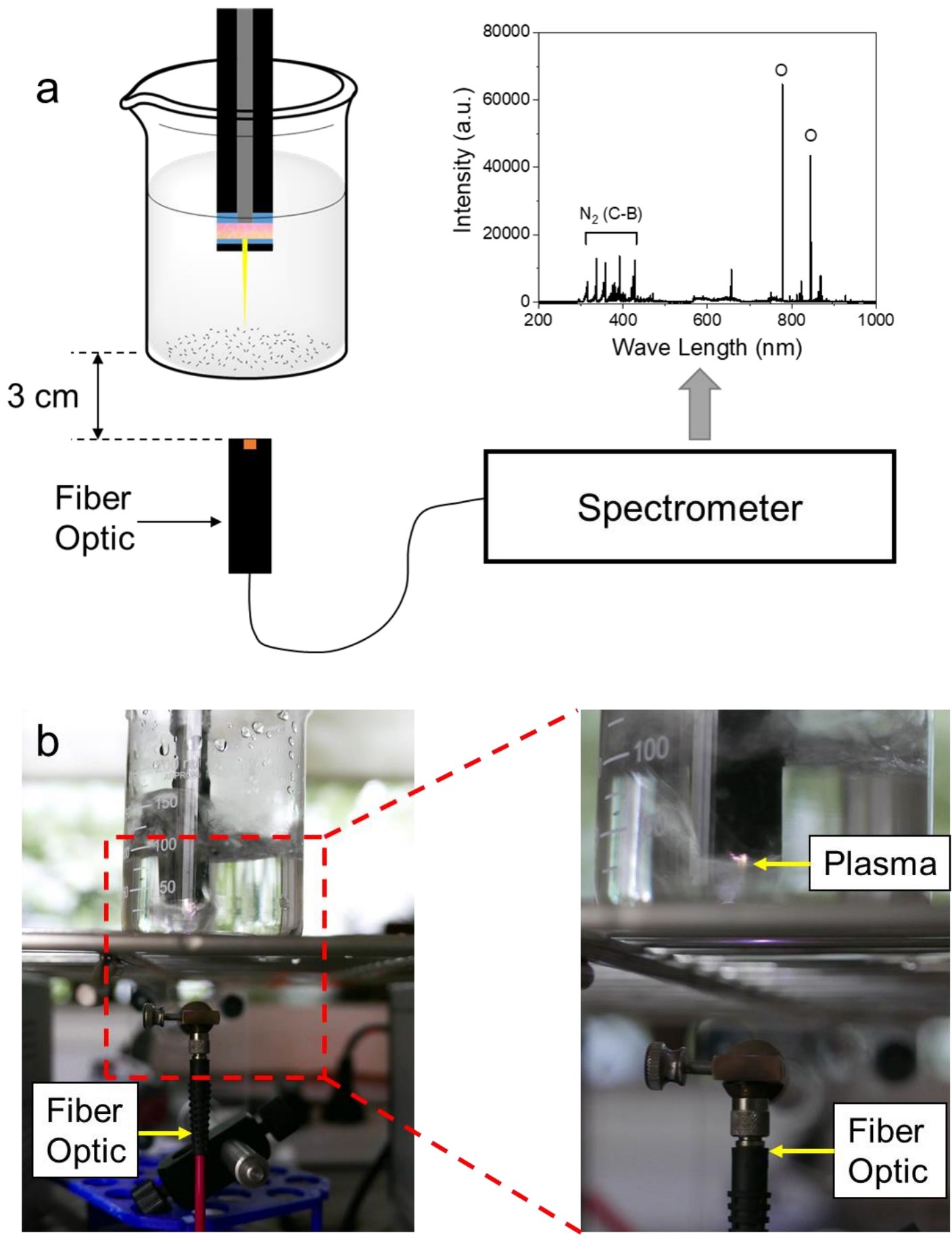

Figure S3. Schematic diagram of OES measurement 


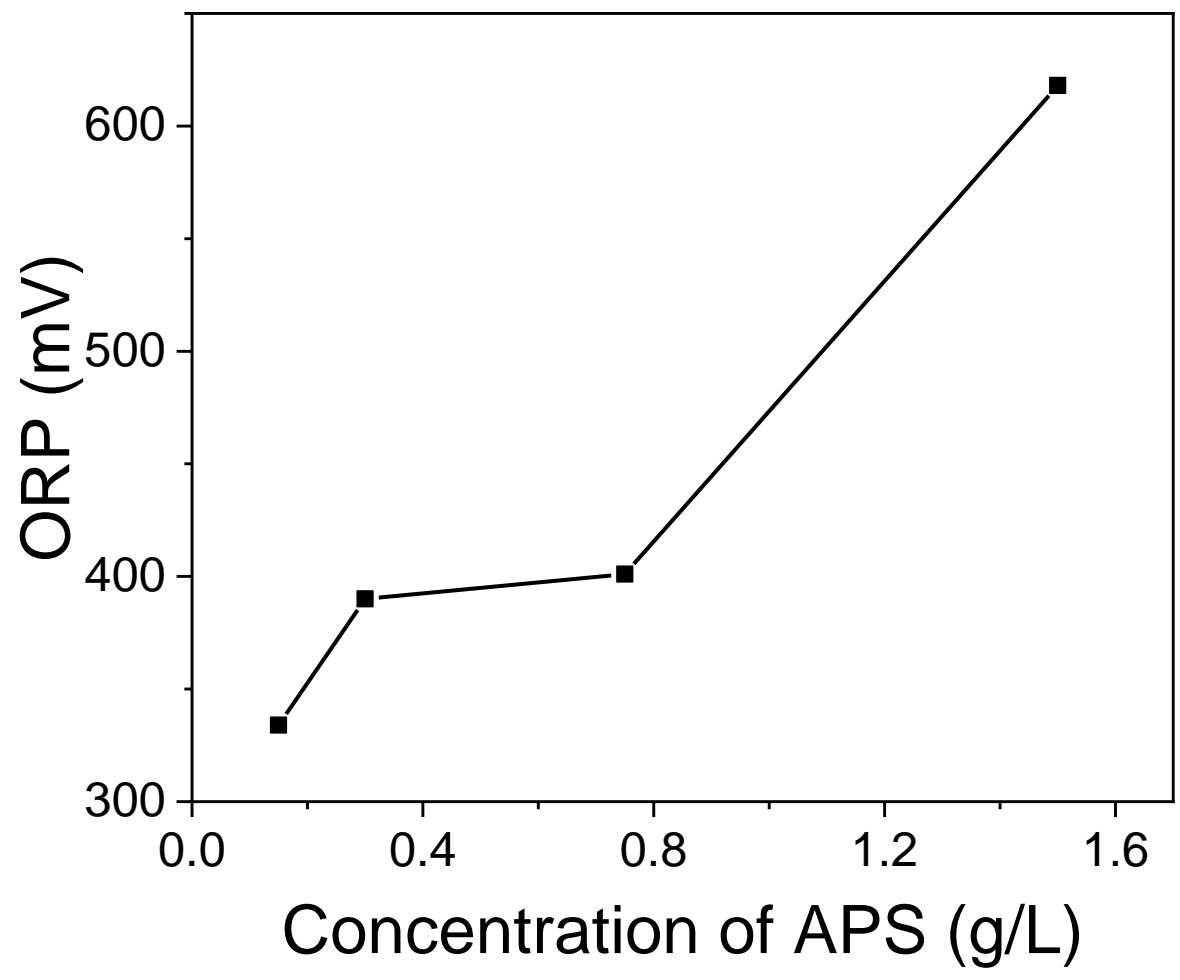

Figure S4. ORP of APS solution 


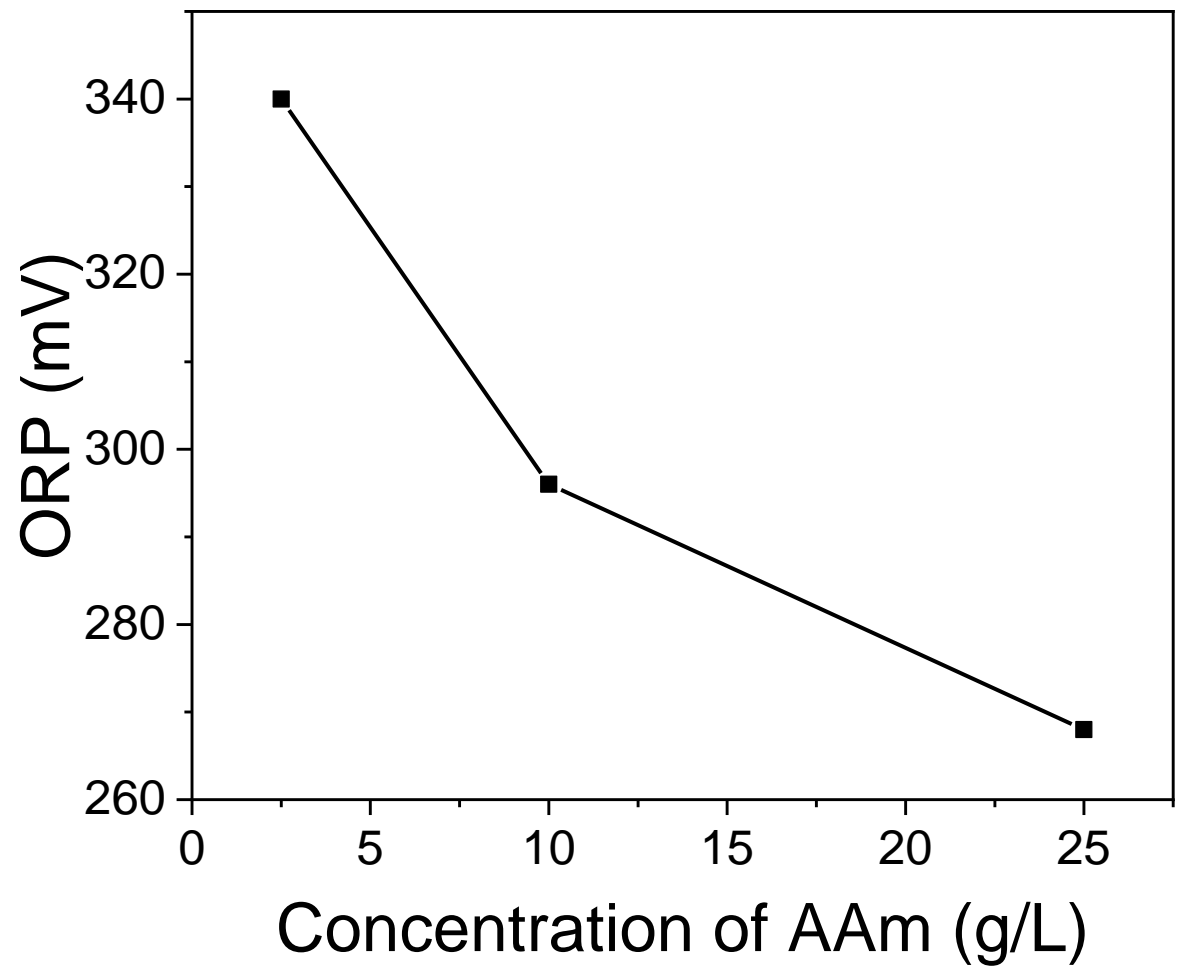

Figure S5. ORP of AAm solution 


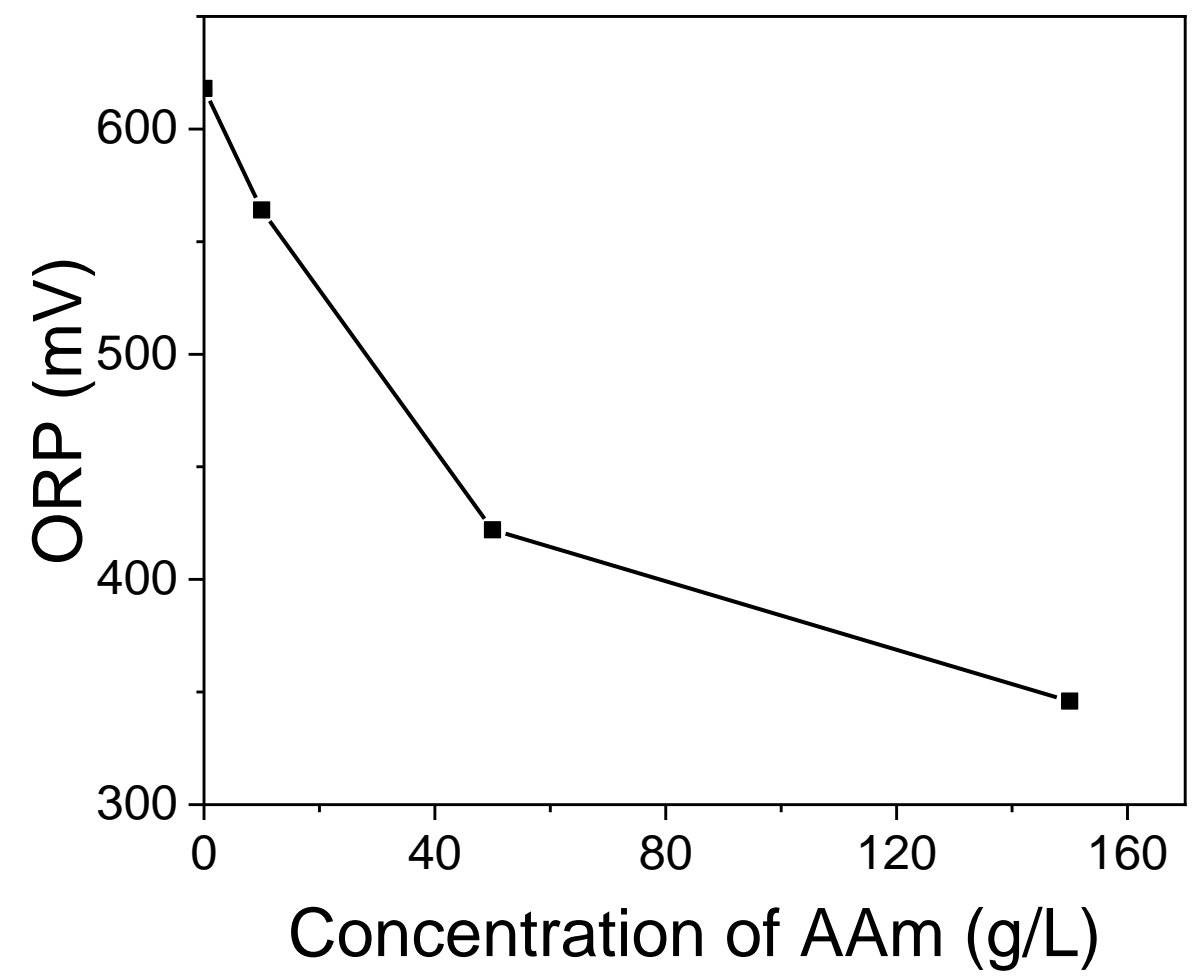

Figure S6. ORP of solution with both APS and AAm. The concentration of APS was 1.5 g/L 


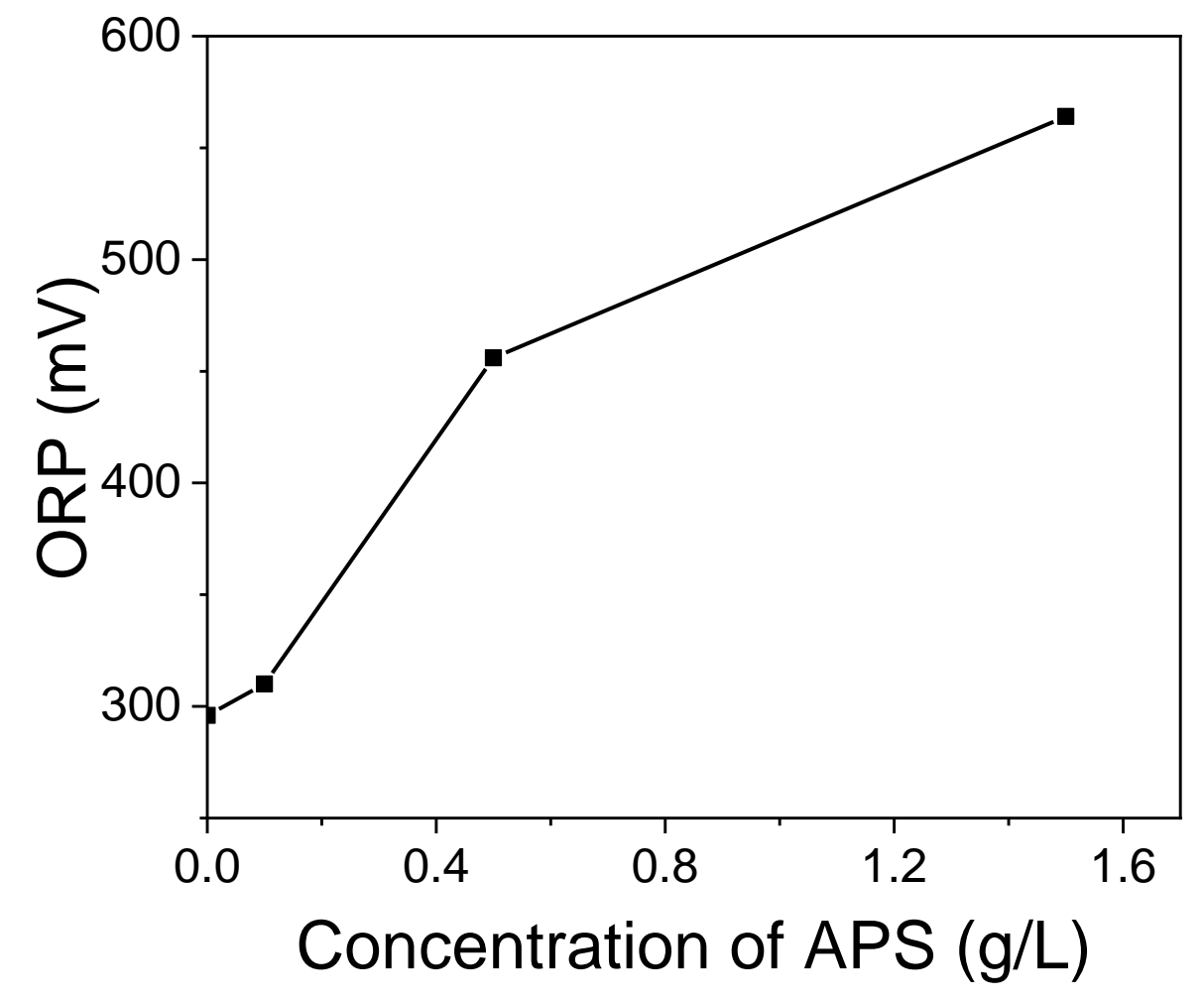

Figure S7. ORP of solution with both APS and AAm. The concentration of AAm was $10 \mathrm{~g} / \mathrm{L}$ 


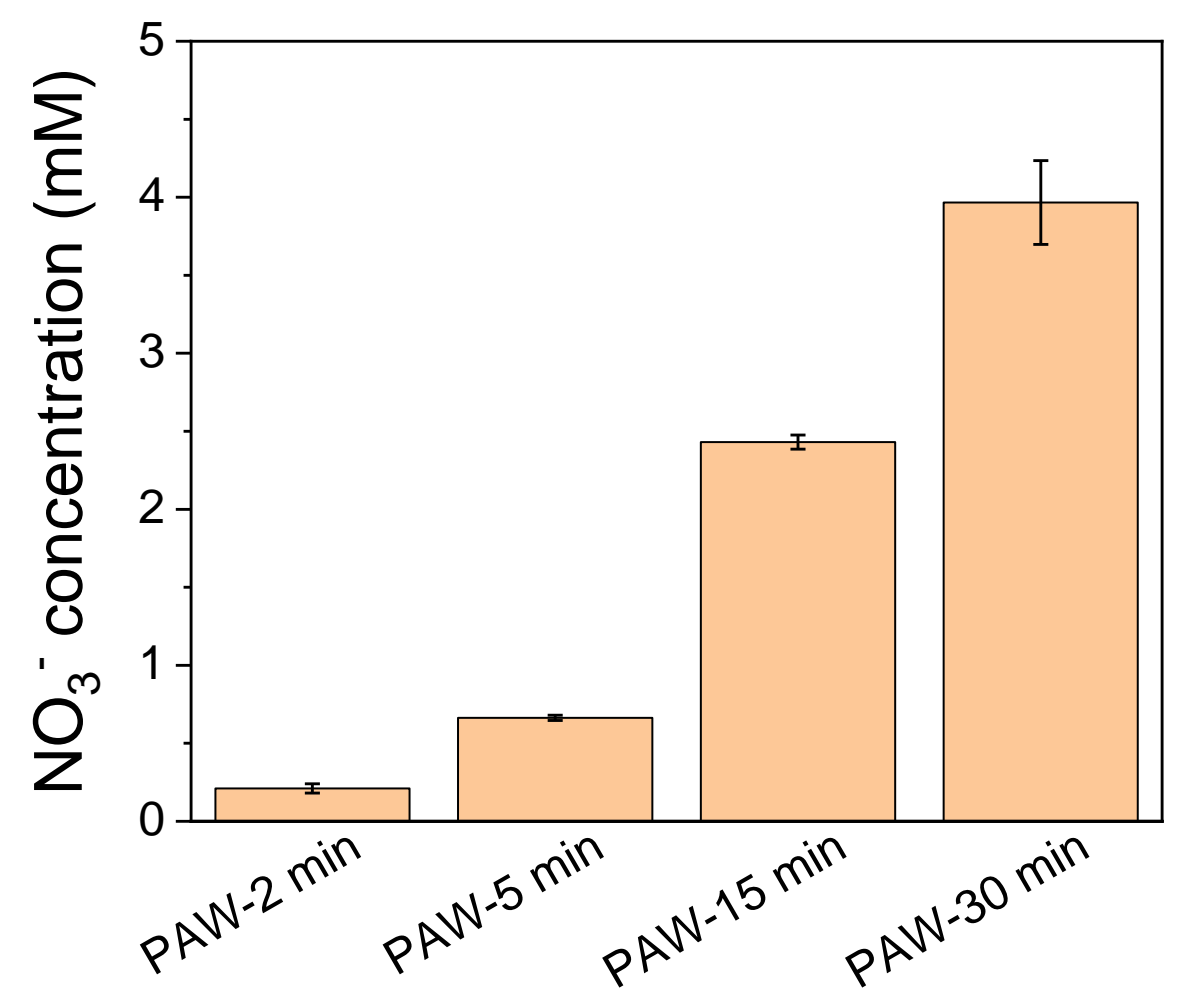

Figure S8. Concentration of $\mathrm{NO}_{3}{ }^{-}$in $\mathrm{PAW}$ 


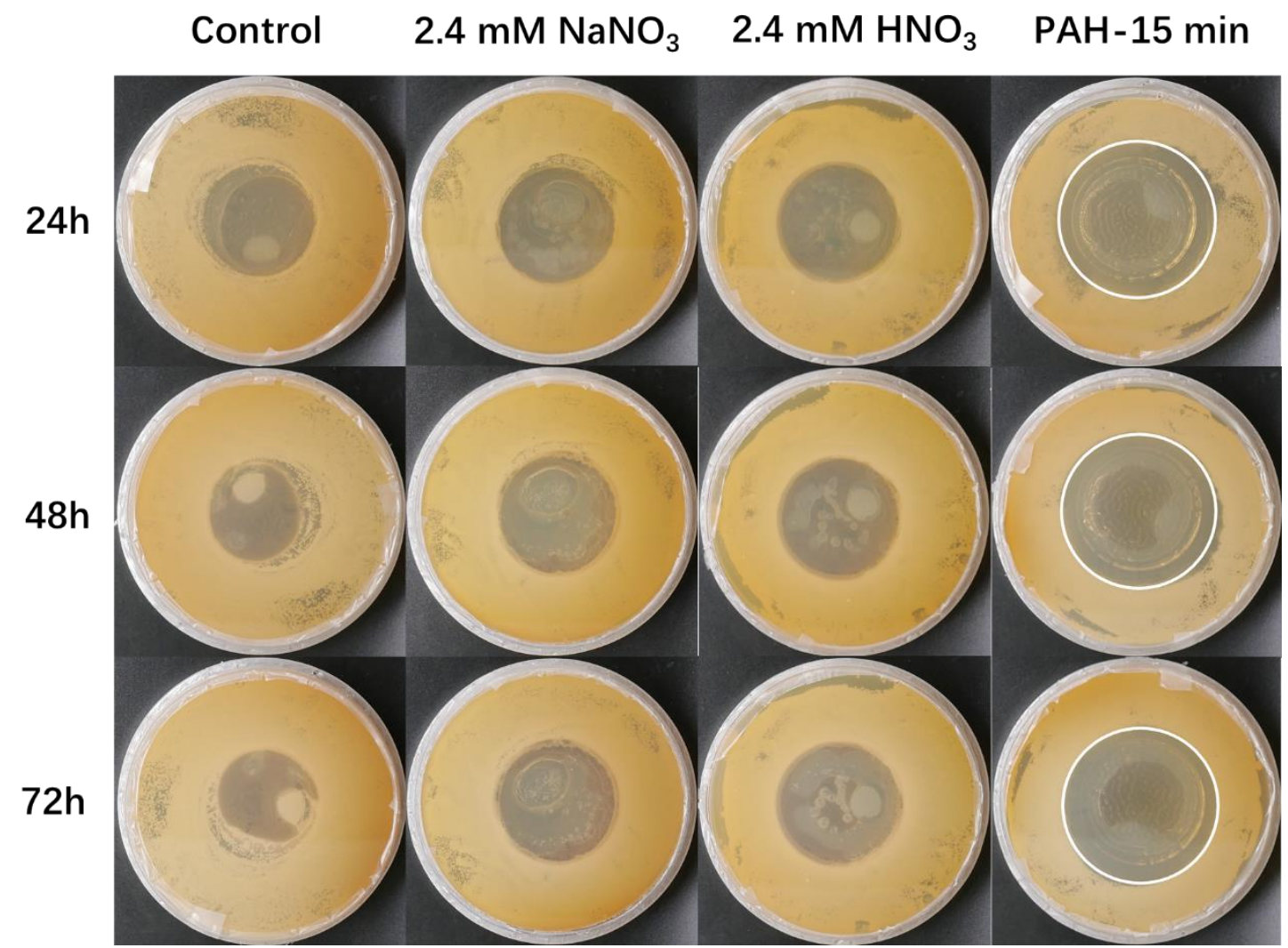

Figure S9. Antifungal activities of $\mathrm{NO}_{3}{ }^{-}$control group hydrogels after $24 \mathrm{~h}, 48 \mathrm{~h}$, and $72 \mathrm{~h}$ contact time. The concentration of $\mathrm{NO}_{3}{ }^{-}$is $2.4 \mathrm{mM}$. 


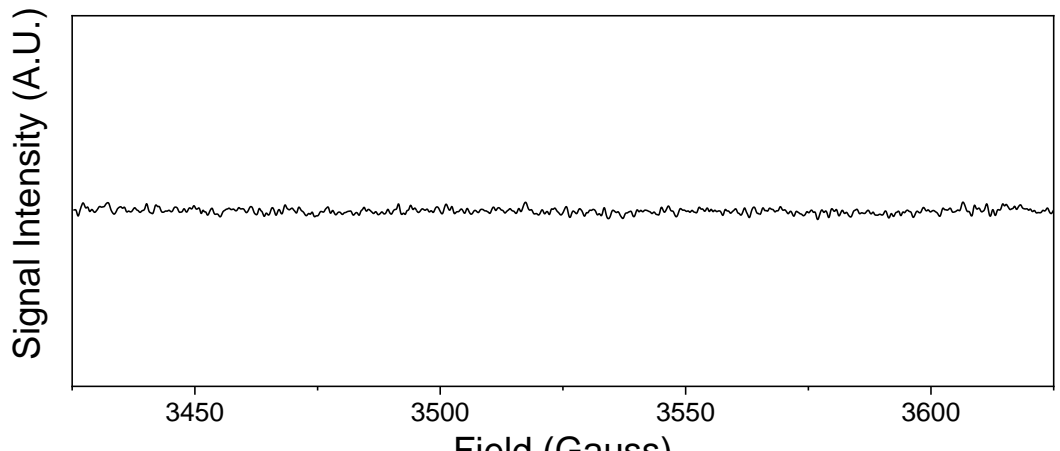

Figure S10. ESR spectra of PAW-30 min. DMPO is used as a spin-trap agent. 